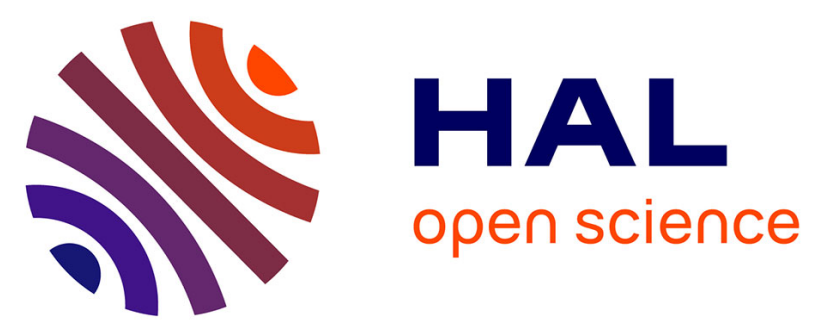

\title{
How does a domestication process modulate oogenesis and reproduction performance in Eurasian perch?
} Amine Khendek, Maud Alix, Sandrine Viot, Yannick Ledoré, Camille Rousseau, Robert Mandiki, Patrick Kestemont, Tomas Policar, Pascal Fontaine, Sylvain Milla

\section{To cite this version:}

Amine Khendek, Maud Alix, Sandrine Viot, Yannick Ledoré, Camille Rousseau, et al.. How does a domestication process modulate oogenesis and reproduction performance in Eurasian perch?. Aquaculture, 2017, 473, pp.206-214. 10.1016/j.aquaculture.2017.02.003 . hal-02994633

\section{HAL Id: hal-02994633 \\ https://hal.univ-lorraine.fr/hal-02994633}

Submitted on 8 Nov 2020

HAL is a multi-disciplinary open access archive for the deposit and dissemination of scientific research documents, whether they are published or not. The documents may come from teaching and research institutions in France or abroad, or from public or private research centers.
L'archive ouverte pluridisciplinaire HAL, est destinée au dépôt et à la diffusion de documents scientifiques de niveau recherche, publiés ou non, émanant des établissements d'enseignement et de recherche français ou étrangers, des laboratoires publics ou privés.

\section{(1) (1) $\$$}

Distributed under a Creative Commons Attribution - NonCommercial - NoDerivatives| 4.0 
1 How does a domestication process modulate oogenesis and reproduction 2 performance in Eurasian perch?

3

4 Amine Khendek ${ }^{\mathrm{a}}$, Maud Alix ${ }^{\mathrm{a}}$, Sandrine Viot ${ }^{\mathrm{a}}$, Yannick Ledoréa ${ }^{\mathrm{a}}$, Camille

5 Rousseau $^{\text {a }}$, Robert Mandiki ${ }^{\mathbf{b}}$, Patrick Kestemont ${ }^{\mathbf{b}}$, Tomas Policar ${ }^{\mathrm{c}}$, Pascal

6 Fontaine $^{\mathrm{a}}$, Sylvain Milla ${ }^{\mathrm{a}^{*}}$

${ }^{a}$ Unit Research Animal and Functionality of Animal Products (URAFPA), University of Lorraine. Boulevard des

8 Aiguillettes, BP 236, 54506 Vandoeuvre-Lés-Nancy, France.

$9{ }^{b}$ Research Unit in Environmental and Evolutionary Biology (URBE), NARILIS, University of Namur (FUNDP),

10 Rue de Bruxelles, 61, B-5000 Namur, Belgium.

$11{ }^{c}$ University of South Bohemia in Ceske Budejovice, Faculty of Fisheries and Protection of Waters, South Bohemian Research Center of Aquaculture and Biodiversity of Hydrocenoses, Zatisi 728/II., 38925 Vodnany,

13 Czech Republic.

* Corresponding author. Tel.: $+\underline{+33383685595}$ fax: $\underline{+33383684001}$; e-mail address: Sylvain.Milla@univ-lorraine.fr 


\section{Abstract:}

The domestication process is accompanied with adaptation of the animals to captive conditions. It induces changes at different levels thereby affecting a variety of biological functions. While there is abundant literature on the domestication effects on growth and stress response in teleosts, the effects on reproduction have received limited attention. In this work, we investigated the domestication effect on reproductive ability of Eurasian perch (Perca fluviatilis L.), a promising candidate for the development of European aquaculture and whose reproductive physiological processes through the domestication history has not been questioned yet.

To address this question, two populations of F1 and "domesticated" females were submitted to a photothermal program allowing the control of gonadogenesis advancement. Gonadosomatic index, $17 \beta$-estradiol levels and oocyte diameter were significantly higher in domesticated population than in F1 one. In contrast, testosterone, 11-ketotestosterone, and vitellogenin levels were found to be higher in F1 females than in their domesticated counterparts. Lower reproductive performance were observed in the domesticated population compared to the $\mathrm{F} 1$ one in terms of survival rate, hatching rate, percentage of eyed stage larvae and percentage of malformations. In conclusion, this study shows that, in this example of domestication process, despite a positive effect on the precocious gonadogenesis advancement and vitellogenesis progress this domestication route negatively affected the reproductive performance.

Keywords: Perca fluviatilis, Recirculating Aquatic System, GnRH, Gonadotropins, Sexual steroids. 


\section{Introduction}

Price (1984) defined the domestication as "the process whereby a population of animals becomes adapted to humans and captivity conditions through one or several combinations of genetic changes throughout the generations". Digard (2003) proposed to define domestication as "the action that men exercise over animals they own, even by raising them". Thus the list of domesticated fish species goes from the range of 25-30 in the first definition to more than 200 according to the definition of Digard (2003). This shows that the concept of domestication still divides opinions within the scientific community. However, everyone agrees that fish populations may undergo, through the domestication process, changes in their genome due to adaptation to environmental stressors, genetic selections (deliberate or not) or inbreeding phenomena (Balon 2004 ; Price 1984). It induces changes at anatomical, physiological and molecular levels thereby affecting a variety of biological functions (e.g. Brummet et al. 2004). There is abundant literature on the domestication effects on growth (Withler and Beacham 1994; Hassin et al. 1997; Tymchuck et al. 2006) and stress response in teleosts (Pickering and Pottinger 1989, 1997; Vandeputte and Prunet 2002; Douxfils et al. 2011). On the one side, it has been shown that globally domestication reduces fish stress response, by rendering them less fearful as showed in salmonids (Pickering and Pottinger 1989,1997; Vandeputte and Prunet 2002), or less sensitive to acute handling stressors in Eurasian perch (Douxfils et al. 2011). But in European sea bass (Dicentrarchus labrax) it has been shown that heritability of cortisol response to stress was low (Volckaert et al. 2012). On the other side, the domestication seems to boost the growth performance (Withler and Beacham 1994; Hassin et al. 1997; Tymchuck et al. 2006). 
Contrary to growth and stress response, the effects of domestication process on reproduction have received limited attention. Moreover, it appears that this field of research has conducted to conflicting results. In the ide (Leuciscus idus), Krejszeff et al. 2009 showed that domestication positively influenced the ovulatory responses following the Ovopel ${ }^{\mathrm{TM}}$ hormonal treatment. In contrast, they showed that domestication exhibited a negative effect on embryo survival. More recently, a study on the same species showed different results by pointing out a lower ovulatory response to Ovopel ${ }^{\mathrm{TM}}$ in the pond-cultured group relatively to wild fish (Ciesla et al. 2013) and no domestication effect was observed on the embryo survival. Moreover, the effect of domestication can be different from one species to another. In Atlantic salmon (Salmo salar) domestication led to an $83 \%$ decrease of the hatching rates (Jonsson and Jonsson 2006). In cod (Gadus morhua), domestication negatively affected fertilization rates, hatching and larvae survival (Salze et al. 2006). In brown trout (Salmo trutta) domestication negatively affected sperm quality (Dannewitz et al. 2004) but had a positive effect on spawning and egg weight (Randak et al. 2006). Consequently, notable differences also exist between the fish families, the fish species and the fish populations. These differences led us to investigate the domestication effects on reproductive ability of Eurasian perch (Perca fluviatilis), a species whose domestication history is still recent, and belonging to a fish family poorly investigated.

Eurasian perch is a freshwater fish species highly valuable in Europe (Fontaine, 2009). The perch market is local and the current production of market-size perch in Europe is thus unable to satisfy the demand, which is mainly centered in the Alpine region (Setälä et al. 2008; Watson, 2008). Consequently to a relative decline of wild stocks due to intensive fisheries, and to an increasing demand for small sized perch especially in Switzerland, intensive perch culture has been developed in the past two decades, and Eurasian perch has become a relevant species in European aquaculture (Fontaine 2004; Watson 2008). Up to now, only one study 
has examined the effect of domestication on Eurasian perch reproduction (Kristan et al. 2012). Results showed a positive effect of domestication on fertilization rates, but a negative effect on ovulation and hatching. Actually, there is no detailed study aiming at understanding the influence of domestication on both the mating performance and the reproductive mechanisms underlying these effects. Our hypothesis is that disruption in the level of the endocrine actors that control the reproductive cycle explains the changes of the reproductive performance along the domestication process.

The aim of this study was to compare two perch populations (F1 and "domesticated"), exposed to a special photothermal program allowing the control of gonadogenesis advancement, in terms of morphological parameters (gonado-somatic index, hepato-somatic index), levels of GnRH and gonadotropins gene expression, sexual steroids and vitellogenin, as well as the oocyte developmental stages and reproductive performance.

\section{Materials and methods}

\subsection{Fish}

Two populations of F1 and "domesticated" perch were studied in this experiment, both originally came from the Geneva Lake (French-Swiss border). F1 breeders came from wild broodstock (F0) collected as eggs directly taken from Geneva Lake. According to the local producer (Lucas Perches, Hampont, France), “domesticated” breeders are generated from seven generations fish raised in captivity, even if the introduction of wild individuals during reproduction seasons cannot be totally excluded. The domestication history of these fish is thus a "black box". The F1 and domesticated breeders were issued from an artificial reproduction completed on November 1st, 2011 and were then raised on the producer facilities, before coming to the URAFPA-MAN facilities located in Nancy (France) on 
127 February $6^{\text {th }}, 2012$, where they were placed in two 6000 L. tanks for growth. At their arrival 128 to our facilities, fish of both populations were 3-months-old. From their hatching, the two 129 studied fish populations (F1 and "domesticated") have thus been raised in equal and standardized husbandry conditions, at the Lucas perches facilities, fish were raised at a temperature range of $18^{\circ} \mathrm{C}-20^{\circ} \mathrm{C}$ and a photoperiod of $13 \mathrm{~L} / 11 \mathrm{D}$ with a blue light or a red light. At the URAFPA-MAN facilities fish were kept at $20^{\circ} \mathrm{C}$ and a photoperiod of $16 \mathrm{~L} / 8 \mathrm{D}$ during the growth period. Fish were daily fed to apparent satiation during the growth period and during the experiment (Le Gouessant pellets $\mathrm{n}^{\circ} 5$, proteins $47 \%$, lipids $13 \%$, ash $6.90 \%$ and fiber $2.2 \%$ ).Fish were handled in accordance with national and international guidelines for protection of animal welfare.

\subsection{Experimentation and water quality management}

Experiment started on May $17^{\text {th }}, 2013$, fish were 18 months old and never spawned before. Breeders of both populations were transferred to 500 L. independent experimental tanks (3 tanks per population with 48 fish per each tank), each tank had his own filtration system and $25 \%$ of the water was changed every month. At the beginning of the experiment, fish weight ranged between $67-137.8 \mathrm{~g}$ for the "domesticated" fish and in the range of 70.4-129.8g for the F1 ones. Both populations were exposed to a photothermal program enable to induce and drive the gonadogenesis (Fontaine et al. 2015) (Fig. 1).

In each tank, water quality was measured three times per week. $\mathrm{pH}$ was maintained between 7.0 and 7.5 by $\mathrm{NaCO}_{3}$ additions. The dissolved oxygen was maintained over of $6 \mathrm{mg} / \mathrm{L}$. The total ammonia $(0,36 \pm 0,53 \mathrm{mg} / \mathrm{L})$ and nitrite $(0,08 \pm 0,12 \mathrm{mg} / \mathrm{L})$ nitrogen were measured using a CARY I spectrophotometer and remained always below $1 \mathrm{mg} / \mathrm{L}$.

Fish were sampled at days T0, T35 (decrease of temperature), T157 (vernalization period) and 295 (increasing of temperature ) after the start of the photothermal program (Fig. 1). Six 
females per tank were caught at each sampling period. The first sampling occurred just before the initial photoperiod decrease. At each sampling date, fish were anesthetized into a Tricaine methanesulfonate (MS-222) bath (120 mg/L, Sigma). Blood was sampled from the caudal vein using a syringe, then stored on ice in heparinized microtubes until centrifuged at $3000 \mathrm{~g}$ for 10 min (Centrifuge Jouan C-412). Aliquots of plasma were stored at $-80^{\circ} \mathrm{C}$ until ELISA analysis was performed. Then, each fish was euthanatized by overanesthetizing in Tricaine methanesulfonate (MS-222) bath (240 mg/L), weighted and dissected for gonad and liver weighting and calculation of the gonadosomatic index (GSI=100 $\times$ gonad weight/total fish weight) and hepatosomatic index (HSI= 100 $\times$ liver weight/total fish weight). For gene expression analysis, the whole brain and pituitary were snap frozen (separately) in liquid nitrogen and stored at $-80^{\circ} \mathrm{C}$.

\subsection{Gonadal histology}

Samples of ovaries were stored in a Bouin-Holland solution for 1 week, washed once with water, twice with $70 \%$ ethanol and stored in absolute ethanol (Abdulfatah et al. 2010). Then, fragments of gonads were cut into 6-mm-thick slices, dehydrated with OTTIX solution (DIAPATH SpA, Italy/MM France) and embedded in a paraffin substitute dubbed Diawax (DIAPATH SpA, Italy/MM France) (adapted from Langeron 1942). Sections of $6 \mu \mathrm{m}$ were cut from the Diawax block and stained with a Masson's trichrome-haematoxylin Gill III (Merck, Darmstadt, Germany), $0.5 \%$ phloxine B (VWR, California, USA) and $0.5 \%$ light green (Sigma, Saint Quentin Fallavier, France) according to Rinchard and Kestemont (1996). The stage of oocyte development was determined according to Wallace and Selman (1981). Observations have been completed with a light upright optical microscope (Nikon Eclipse NiU), Nikon BR software (Nikon France, Champigny sur Marne, France). 


\subsection{Total RNA extraction and reverse transcription}

Total RNA was extracted from the brain and pituitary using TRIzol reagent (VWR, CTRIZ02) according to the manufacturer's protocol. Concentration of total RNA was measured by UV absorption spectrometry using a Jasco V-630 Spectrophotometer. DNase treatment (DNase I Thermo Fischer Scientific, EN0521) was performed according to manufacturer's recommendations. Reverse transcription was performed with M-MLV reverse transcriptase (Sigma, M1302) according to the manufacturer's recommendations. For each sample $1 \mu \mathrm{g}$ of total RNA was used. Reaction mixes have been done following manufacturer's recommendations. Each reverse transcription mix was incubated at $37^{\circ} \mathrm{C}$ for $50 \mathrm{~min}$ and then heated at $90^{\circ} \mathrm{C}$ for $10 \mathrm{~min}, \mathrm{c}-\mathrm{DNA}$ samples were finally kept at $-80^{\circ} \mathrm{C}$.

\subsection{Gene expression analysis}

Primers were designed based on a multiple alignment of sequences available in the NCBI data base, targeting conserved regions of the FSHb and LHb-subunits, the GnRH 3 as well as the $\beta$-Actin as housekeeping gene.

In order to isolate and to sequence $P$. fluviatilis FSHb, LHb-subunits and the GnRH 3 cDNAs from the brain, a PCR reaction was performed. PCR conditions were as follows: denaturing cycle of $95^{\circ} \mathrm{C}$ for $2 \mathrm{~min}$, followed by 35 cycles of $95^{\circ} \mathrm{C}$ for $1 \mathrm{~min}, 58^{\circ} \mathrm{C}$ for $1 \mathrm{~min}, 72^{\circ} \mathrm{C}$ for 1 min, followed by a final elongation step of $72^{\circ} \mathrm{C}$ for $5 \mathrm{~min}$. PCR products were checked on $1 \%$ agarose gel electrophoresis. The single obtained band corresponding to the expected product size was excised from the gel and the amplicon was purified with E.Z.N.A. Pure Kit (VWR, D6493-01). Purified products were cloned employing the InsTAclone PCR Cloning KIT (Thermo Fischer Scientific, K1214), and plasmids of 2 days cultures of bacterial colonies (Escherichia coli). Plasmids were analyzed by PCR using M7 universal primers and agarose gel to confirm the size of the inserted cDNA. Automated sequencing was performed 
(ABI3730XL DNA sequencer, Macrogen, Korea). Upon gene identification, primers for quantification were designed on two different exons with the FastPCR software V6.5. (Table $1)$.

Real-time PCR was carried out with a StepOne Plus q-PCR Cycler (Applied Technologies) using QUANTA SYBR green reagent (VWR, 733-1382) in a $20 \mu \mathrm{L}$ reaction volume $(5 \mu \mathrm{L}$ diluted cDNA, $2.5 \mu \mathrm{L}(600 \mathrm{nM})$ of each primer, $10 \mu \mathrm{L}$ of 2-fold diluted SYBR-Green solution) under the following conditions: $95^{\circ} \mathrm{C}$ initial denaturation for $10 \mathrm{~min}$, followed by 40 cycles of $95^{\circ} \mathrm{C}$ denaturation for $30 \mathrm{~s}, 60^{\circ} \mathrm{C}$ primer annealing and extension for $1 \mathrm{~min}$. All PCRs were run in duplicate. Expression was determined by the comparative CT method (DDCT) considering a calibrator sample (pooled brain or pituitary cDNA).

A melting curve analysis was carried out to ensure assay specificity. The absence of amplified genomic DNA was validated by comparing the CT obtained in samples with and without DNase treatments and by designing the primers on two different exons. Samples were normalized to $\beta$-Actin mRNA.

\subsection{Hormone assays}

$17<$ beta $>$-Estradiol (E2, ng/mL) was assayed on $50 \mu \mathrm{L}$ of plasma using the DIAsource E2ELISA kit (DIAsource, KAP0621). When necessary, dilution from 1/20 to 1/70 of the plasma samples was performed. Sensitivity was $5 \mathrm{pg} / \mathrm{ml}$. CV intra-assay varied between 3.1 and $2.6 \%$ and CV inter-assays varied between 4.7 and $2.4 \%$ for low and high levels, respectively.

Testosterone $(\mathrm{T}, \mathrm{ng} / \mathrm{mL})$ was assayed on $25 \mu \mathrm{L}$ of plasma using the DIAsource Testosterone ELISA Kit (DIAsource, KAPD1559). When necessary, a dilution 1/2 of the plasma samples was performed. Sensitivity was $83 \mathrm{pg} / \mathrm{mL}, \mathrm{CV}$ intra-assay varied between 1.5 and $9.5 \%$ and CV inter-assays varied between 7.6 and $8.7 \%$ for low and high levels, respectively. The androgen 11-ketotestosterone $(11 \mathrm{KT}, \mathrm{ng} / \mathrm{mL})$ was assayed on $50 \mu \mathrm{L}$ of plasma diluted $1 / 50 \mathrm{in}$ 
ELISA buffer using the Cayman 11-keto Testosterone EIA Kit (Cayman, 582751) and sensitivity was $1.3 \mathrm{pg} / \mathrm{mL}$. CV intra-assay varied between 2.6 and $8.4 \%$ and CV inter-assays varied between 9.4 and $12.1 \%$ for low and high levels, respectively. Plasma 17<alpha>,20<beta>-dihydroxy-4-pregnen-3-one (DHP, ng/mL) was assayed using radioimmunoassay according to Fostier and Jalabert (1986) adapted by Mandiki et al. (2005), following two extractions with cyclohexane/ethyl acetate (v/v). The DHP antibody was provided by Dr A. Fostier (INRA, Rennes, France).

Cortisol was assayed on $20 \mu \mathrm{L}$ of plasma using the DIAsource Cortisol ELISA Kit (DIAsource, KAPDB 270). The intra-assay coefficient of variation was 5.6\%, the inter-assay coefficient of variation was $6.9 \%$. The detection limit was $2.5 \mathrm{ng} / \mathrm{mL}$.

\subsection{Vitellogenin assay}

Vitellogenin was indirectly estimated with Alkali-labile phosphate levels (ALP, $\mu \mathrm{g} / \mathrm{mL}$ ). ALP levels were assayed on $80 \mu \mathrm{L}$ of plasma. Plasma samples were first centrifuged for precipitation of high molecular weight proteins with trichloroacetic acid (20\%). The pellet was then washed with absolute ethanol, chloroform solution - di-ethyl ether - absolute ethanol (1:2: 2), acetone and finally the di-ethyl ether. The dried pellet was then dissolved in a $\mathrm{NaOH}$ solution ( $2 \mathrm{~N}$ ) brough to $100^{\circ} \mathrm{C}$ for $15 \mathrm{~min}$, and then the phosphate release was neutralized by adding cold $\mathrm{HCl}(2 \mathrm{~N})$. Phosphates are then assayed by the method of Stanton (1968) using a phosphorus standard solution for calibration, addition of molybdic acid and reducer solutions and finally by reading the absorbance at $660 \mathrm{~nm}$ with a spectrophotometer.

\subsection{Aromatase assay}

Aromatase activity was measured as the specific release of tritiated water produced by conversion of $\left[1 \beta-\mathrm{H}^{3}\right]$-androstenedione to estrone, as previously described by Noakson et al. 
(2001) with some modifications (Mandiki et al. 2005). Fifteen milligrams of frozen tissue (gonads) were homogenized in a buffer solution $(50 \mathrm{mM}$ potassium phosphate, $250 \mathrm{mM}$ sucrose and $10 \mathrm{mM}$ dithiothreitol $\mathrm{pH} 7,4 ; 1: 10)$. A tenth of the homogenate were added of a NADPH-substrate system consisting of $1 \mathrm{mM}$ NADPH, $25 \mathrm{nM}$ Androst-4-ene-3, 17-dione, $\left[1 \beta-{ }^{3} \mathrm{H}(\mathrm{N})\right] 275 \mathrm{nM}$ Androst-4-ene-3, 17-dione in the buffer solution and incubated with gentle shaking for $60 \mathrm{~min}$ at $30^{\circ} \mathrm{C}$. The reaction was stopped by adding trichloroacetic acid. Samples were then centrifuged and the supernatant extracted with chloroform, the bottom contained the protein. The aqueous phase was washed with dextran (5\%)-activated charcoal $(0.5 \%)$, centrifuged, and an aliquot of the supernatant was added to a liquid scintillating to determine the radioactivity due to the presence of $\left[{ }^{3} \mathrm{H}\right] \mathrm{H}_{2} \mathrm{O}$. For this purpose a liquid scintillation counter was used. The Lowry method was used to determine protein concentration after denaturing the protein with $\mathrm{NaOH}$. The aromatase activity was expressed in fmol $\mathrm{min}^{-1} \mathrm{mg}^{-1}$ protein.

\subsection{Spawning season and reproductive performance}

Spawning season started on March $25^{\text {th }}, 2014$ and finished on April $3^{\text {th }}, 2014.77 \%$ of the females spawned during the spawning season in the F1 population and $78 \%$ of the females spawned in the "domesticated" one. Spawning was induced by temperature increase at the end of the photothermal programme and no hormonal treatment was used during the experiment.

Males and females were kept together in the same tanks. Females were stripped every day during the spawning season at 5:00 AM. When a female was ovulating, ribbons were collected in a dry basin and fertilized with $1 \mathrm{~mL}$ of sperm originated from three different males, in order to optimize the fertilization success. Ribbons were then transferred into incubators and maintained at constant temperature $\left(13 \pm 0,5^{\circ} \mathrm{C}\right)$. After $24 \mathrm{~h}, 48 \mathrm{~h}, 72 \mathrm{~h}$ and $120 \mathrm{~h}$ post fertilization, samples of approximately 200 eggs from each ribbon were observed to 
calculate survival rates. Hatching started at 8 days post fertilization. Larvae were measured and analyzed for malformations (sclerosis, lordosis, yolk bag malformations) with a binocular microscope, on fixed embryos ( $\mathrm{n}=6$ spawns).

\subsection{Statistical analysis}

Data are expressed as mean \pm standard deviation with individual fish as the experimental unit. Normality of data and homogeneity of variances were tested using Shapiro-Wilk and Levene test, and data were either log-transformed or arcsin square-root transformed (for data expressed in percentage) when needed. When data respected the assumptions of normality, a two-way analysis of variance (ANOVA) with two independent factors (population and time) was performed followed by LSD post hoc tests to identify significant differences. The level of significance used in all tests was $\mathrm{p}<0.05$. When data were not normally distributed, a Kruskal-Wallis test was performed followed by the nonparametric Mann-Whitney test. All statistical analyses were performed using the STATISTICA software (StatSoft, Tulsa, USA).

\section{Results}

\subsection{GSI and gonadal development stages}

During the first month of the experiment (T0 to T35), females of both populations had a low GSI (below 1\%) (Fig. 2). Significant increase of the GSI was observed after five months (T157) $(\mathrm{P}<0.05)$, no significant difference was observed between the two populations until T157. At T295, the "domesticated" females showed a significantly higher GSI $(\mathrm{p}<0.05)$ in comparison with the F1 ones (Fig. 2, $\mathrm{P}<0.05$ ). Histological analysis revealed that during the first five weeks of the photothermal program, both female populations showed immature gonads with more than $90 \%$ of protoplasmic oocytes. Since T157 both populations showed 
more advanced gonad maturation and no significant difference between the two populations was pointed out (Fig. 3). However, the protoplasmic oocyte diameter was significantly more elevated for the "domesticated" females $(109 \pm 19 \mu \mathrm{m})$ than for the F1 ones $(104 \pm 11 \mu \mathrm{m})$ at T35 ( $p<0.05)$. The same observation was noticed at T295 with $(152 \pm 13 \mu \mathrm{m})$ for "domesticated" females and $(138 \pm 12 \mu \mathrm{m})$ for the F1 ones $(\mathrm{p}<0.05)$. At T295, "domesticated" females showed a more advanced gonadal development than the F1ones with respectively $54 \%$ and $39 \%$ of late vitellogenesis oocytes (Fig. 3), even if there was no significant difference in terms of the oocyte diameter for vitellogenic oocytes.

\subsection{Sexual steroids, vitellogenin and aromatase}

Values for plasma $17 \beta$-estradiol (E2) were the lowest levels at T0 and T35 for both female populations (less than $0.5 \mathrm{ng} / \mathrm{mL})$ (Fig. 4A), with a significantly higher level $(\mathrm{p}<0.05)$ for domesticated females at T35 in comparison with F1 ones. At T157, plasma E2 levels significantly increased for both populations in comparison with T35 levels. At T295, a drop of E2 levels was noticed in the F1 population, so E2 values were significantly higher $(p<0.05)$ in domesticated females than in F1 ones.

Plasma Testosterone (T) levels started to increase since T157 until the end of the experiment for both populations (Fig. 4B). Significant difference was observed at T157 when plasma T levels were significantly higher for F1 females in comparison with the "domesticated" fish $(\mathrm{p}<0.05)$. Plasma vitellogenin levels followed a similar pattern of change as those observed for T (Fig 4C), with a significant difference $(\mathrm{p}<0.05)$ at T157 in favor of F1 females. 11Ketotestosterone (11-KT) levels remained low for both female populations until T295, when 11-KT levels significantly increased but no significant difference between the two groups was observed (Fig. 4D). 
Plasma DHP levels showed an increasing pattern along the experimental time-course for both populations (Fig. 5A) and no significant difference was observed between the two groups. In the same way, the aromatase showed an increasing activity, but no significant difference was registered between the two groups (Fig. 5B).

\subsection{GnRH and GtHs gene expressions}

GnRH mRNA levels did not show any significant difference between the two populations (Fig. 6A, B), but showed a two-fold increase at T35 and remained at this level until T157. BFSH mRNA levels showed a quick increase between T0 and T35 for both populations (Fig. 6C, D), and were significantly higher in the F1 perch brains in comparison with their "domesticated" counterparts at T157 and decreased at the last sampling time. In both brain and pituitary tissues (Fig. 6E, F), $\beta \mathrm{LH}$ mRNA levels increased coincidently with advancing ovarian development. Significant differences in favor of the F1 population were observed at T35 and T295 in the brain (p<0.05) (Fig. 6E) and pituitary (p<0.005) (Fig. 6F).

\subsection{Plasma cortisol}

Plasma cortisol levels showed a significant difference between the two groups with higher values found in the F1 population $(\mathrm{p}<0.05)$ at T35 than the "domesticated" fish (Fig. 7). But, the difference between the two groups was not significant at the other sampling times.

\subsection{Reproductive performance}

The development rates at $24 \mathrm{~h}, 48 \mathrm{~h}, 72 \mathrm{~h}$ and $120 \mathrm{~h}$ post-fertilization were evaluated for the two populations. The F1 population showed a better survival rate than the "domesticated" one at the four observation times (Table 4) $(\mathrm{p}<0.05)$. The F1 population showed a higher eyed stage larvae percentage and a higher hatching rate than the "domesticated" population. F1 
population larvae were of better quality than their "domesticated" counterparts in regard of percentage of deformities $(\mathrm{p}<0.05)$.

\section{Discussion}

In the present study, changes in gonadosomatic index in the population of "domesticated" fish corresponds to the profile described by Migaud et al. (2002), and the maximum level of GSI reached at the last sampling time $(18.5 \pm 3.2 \%)$, is consistent with the level obtained in Eurasian perch females by Kristan et al. (2012). These GSI values were significantly higher than those registered in F1 fish $(15.8 \pm 3.2 \%)$, being themselves lower than those recorded by Migaud et al. (2003) and Kristan et al. (2012) in wild Eurasian perch populations (F0). In agreement with the above GSI results, "domesticated” females showed a slightly more advanced gonadal development than the F1 ones with respectively $54 \%$ and $39 \%$ of late vitellogenesis oocytes at the end of the photothermal program, and a more elevated protoplasmic oocyte diameter than the F1 ones. This further supports the more advanced gonadogenesis in the "domesticated" fish by comparison to their F1 counterparts. These results do not corroborate previous observations made by Kristan et al. (2012) in Eurasian perch females. Differences between farmed and wild perch have been suggested to be caused mainly by unsuitable feed for the farmed fish (Bell et al. 1997; Kestemont et al. 1999; Izquierdo et al. 2001; Kestemont et al. 2008; Henrotte et al. 2010). These authors stated that, to address lower reproduction in farmed perch, it is necessary to improve the diet by adding prey fish and a larger proportion of natural ingredients to the feed. In the experiment of Kristan et al. (2012) wild fish were fed with prey fish and farmed ones with both industrial food and prey fish, while in our study, both populations were fed only by industrial food. This could be one element explaining the discrepancy between the two studies. 
377 Moreover, we cannot rule out the implication of other external factors (e.g. type of

378 photothermal program) and internal factors (e.g fish age) in the monitoring of divergent data.

379 Our wild population is a F1 generation issued from F0 broodstock caught as eggs from the

380 wild (Geneva Lake) and reared in artificial conditions during their whole life. The wild

381 population studied by Kristan (2012) is a wild population reared in ponds and transferred in

382 artificial conditions for the experiment, which implies acclimation phenomena due to the

383 transfer to artificial conditions, which may in turns alter gonad maturation and reproduction.

384 In addition, we cannot exclude the influence of internal factors like fish age that has been

385 shown to influence reproductive capacity in teleosts (Abi-Ayad, 1998). Our fish were

386 eighteen months old for both populations, whereas fish studied by Kristan (2012) were three

387 years old. The geographical origins, and by consequence, potentially the genetic patrimony, is

388 another internal factor that can impact fish reproduction and justify divergent results.

While the gonadogenesis was more advanced in the "domesticated" population, the final reproductive outcomes were markedly better in the $\mathrm{F} 1$ fish. The fertilization rate monitored at 24h was almost 3 -fold higher in the F1 fish (78 $35 \%)$ in comparison with the "domesticated" group (28 $\pm 29 \%$ ). The fecundity rates observed by Kristan (2012) were more elevated (90\%) in both populations. Kouril and Hamackova (1999) reported 60-95\% fertilization of eggs in wild perch after artificial stripping which is in agreement with our values for the F1 population. This difference of fertilization rates is an additional indication that the egg quality

397 in Eurasian perch is highly variable between the studies and also within the same population. The highest contrast between farmed and F1 perch in the parameters of egg quality was recorded after the evaluation of hatching rates. A really poor percentage of hatching rate was obtained for the farmed fish $(2 \pm 2 \%)$, slightly lower that the data provided by Kristan et al. 
(2012) in other farmed population. This poor ova quality could be explained by the fact that "domesticated" fish exhibited a faster gametogenesis than the F1 ones and they did not accumulate enough nutrients for embryo development. This better egg quality in F1 fish was also confirmed by comparing the percentages of malformations between both populations. Anyway these results and those of Kristan et al. (2012) suggest that "domesticated" broodstock in Eurasian perch exhibit lower reproductive performance than fish at an earlier stage of domestication.

In the present study, the better reproductive performance in F1 are a priori surprising regarding the gonadogenesis and oocyte development results. To understand the physiological mechanisms that are behind these differences, we investigated some physiological actors driving the control of oogenesis control. The estrogen 17- $\beta$ estradiol (E2) levels were higher in the "domesticated" fish than in the F1 fish, which is in agreement with the GSI results. Contrarily, testosterone levels were higher in F1 females than in "domesticated" ones. We tried to understand these opposite results by measuring aromatase activity (enzyme which converts testosterone to 17-beta estradiol). No significant difference in aromatase activity was found between the two populations while we expected a decline in aromatase activity for the F1 population. Our observation cannot explain this difference in sexual steroids levels between the two populations. However, E2 being the principal mediator of vitellogenin production and incorporation in the oocytes (Lubzens et al. 2010), these more elevated E2 levels in domesticated fish should have been accompanied with higher levels of vitellogenin in the plasma. However opposite results were found. These conflicting observations might be explained by three simultaneous phenomena: firstly Eurasian perch displays strongly elevated testosterone levels by comparison to other fish species and these testosterone levels are 20-50fold higher than the E2 level (Milla et al. 2009a). Secondly, like E2, testosterone is a 
stimulator of vitellogenin production in fish (Ramezani-Fard et al. 2013). Thirdly, more elevated testosterone levels were measured in the F1 perch than in the domesticated ones. All together, we speculate that the higher vitellogenin level measured in F1 fish would be more explained by the differential testosterone level between both groups rather than the classically described E2 involvement. Concerning 11 keto-testosterone, given the low level observed in comparison with the testosterone level and the absence of contrasted concentrations between both groups, we consider that this sexual steroid was not a major actor explaining this divergence of oogenesis progress between F1 and domesticated fish.

Moreover, to explain the divergence in oogenesis and reproductive performance between the two populations, we investigated the plasma 17 $\alpha, 20 \beta$-dihydroxy-4-pregnen-3-one (DHP), which is the maturation inducing steroid (MIS) in percids (Nagahama et al. 1987). Our hypothesis was that, a difference in kinetics of the final oocyte maturation between the two populations would be at the origin of the reproductive performance divergence. But plasma DHP levels which shows a classical kinetics of change did not display different levels between the two female groups. However it has been reported that another MIS is associated with the final oocyte maturation control in some perciform species: it is the $17 \alpha, 20 \beta, 21$ trihydroxy-4-pregnen-3-one (20ß-S) (Thomas 1988; Asahina et al. 1991 ; Modesto and Canario 1993; King et al. 1994), we can imagine that in perch, final oocyte maturation could be controlled by the combined action of DHP and $20 \beta-S$, but we cannot exclude the hypothesis that the DHP could be the principal MIS in perch but it has to be sampled more frequently during the final oocyte maturation phase. All combined, our hypothesis is that this domestication process displayed distinct effects according to the time-course of oogenesis. Indeed, farmed fish exhibited an earlier gonadogenesis and vitellogenesis than F1 ones, then turning to depreciative effects on final oogenesis, oocyte quality, finally traduced by poor reproductive performance. 
452 Several studies have reported the effect of domestication on reproduction efficiency in many

453

454

455

456

457

458

459

460 species (Dannewitz et al. 2004; Salze et al. 2005; Randak et al. 2006; Jonsson and Jonsson 2006; Krejszeff et al. 2009; Kristan et al. 2012; Ciesla et al. 2013).These data suggest that physiological changes occur during the domestication process due to farming conditions. However, these studies do not provide information about the endocrine mechanisms in broodstock explaining these changes in reproductive capacity. As the level of sex steroids is modified in our study, we hypothesized that a disruption of the gonadotropic axis occurred during the domestication process. Significant differences between the two populations were monitored in the level of gonadotropin gene expressions in the brain and pituitary, while GnRH gene expression was not affected. However, we only investigated the GnRH3 form in our experiment, but there is another form involved during the reproduction in fish which is the GnRH1 (Yaron et al. 2003) and which could be affected as well during the domestication process. These results support the hypothesis of a gonadotropic axis disruption, starting at the gonadotropic level affecting in turns the secretion of sexual steroids in the gonad. As the level of FSH and LH transcripts were higher in F1 fish, in particular at the two last sampling times, we think that the more markedly rise in testosterone level in this population is due to LH rise, then leading to a better reproductive performance in F1 fish. Indeed, blood plasma testosterone is regulated after exposure to the LH agonist hCG in perch females at the end of the reproductive cycle (Milla et al. 2009a). However, we cannot rule out the fact that the measures of FSH and LH transcript levels might not reflect the circulating levels of GTHs. Moreover, the hormonal differences observed between the two populations might reflect a differential threshold of action of these hormones between the two populations.

Kristan (2012) proposed that the stress state of fish would explain the differences in the reproductive performance between the two populations. Even if there was not any problem in 
terms of water quality, infection or mortality, the level of cortisol were not low during this experiment and the level was higher in F1 fish before the alveoli cortical stage of the cycle. Consequently, in accordance with the proposal of Kristan, we cannot rule out the fact that the differential cortisol levels or sensitivity to stressful conditions led to differential advancement of early gonadogenesis between the two groups of fish, stress and cortisol being major modulators of fish reproduction (Barton 2002; Milla et al. 2009b; Schreck 2010). But, this precocious difference alone would not be sufficient to explain the major differences in the reproductive performance, as fish were probably in the same level of stress state since the vitellogenesis stage.

In conclusion, this study showed that this domestication route negatively affected the reproductive performance. However, some conflicting results were observed about the reproductive physiological parameters: on the one hand, this domestication process advanced the start of gonadogenesis until the start of the vitellogenesis period, probably caused by more precocious E2 rise. Then, the lower level of gonadotropins transcripts and testosterone potentially led to a drop in vitellogenin in comparison to F1 fish, further affecting the reproductive success. This study showed that this domestication process negatively affected reproduction, so more attention should be paid by the farmers to the choice of renewing broodstock in particular when they maintain fish coming from several generations of domestication in their facilities,

Funding. This study was supported by the FranceAgrimer establishment (French establishment of national agricultural and marine products) contract number: 2013-1566, and partly supported by projects CENAKVA (No. CZ.1.05/2.1.00/01.0024) and CENAKVA II (No. LO1205 under the NPU I program). 
Authors contributions. Amine Khendek was responsible for the carrying out data analyses and wrote the main part of the manuscript, and performed the gene expression analysis. Sylvain Milla, Pascal Fontaine and Tomas Policar initiated the research and/or managed the work and gave final approval for submission. Sandrine Viot and Camille Rousseau performed the plasma steroid assays and histological analysis, Maud Alix managed the spawning season and compared the reproductive performance of both populations, Yannick Ledoré took care of fish daily and managed the samplings; SNM Mandiki and Patrick Kestemont performed the enzymatic activity assay and RIA assay for aromatase activity and DHP. All authors read and approved the manuscript.

Aknowledgments. The authors are grateful to the INRA institute of Champenoux, France for access to histological equipment and their help, and to PB2P team (University of Lorraine, France) for access to the bacterial culture equipment for cloning GnRH and GtHs genes. We would like to thank Vincent Joussemet for his help during the spawning season (University of Lorraine, France) and all the members of team DAC (University of Lorraine, France) who helped during fish sampling.

\section{References}

Abdulfatah, A., Fontaine, P., Kestemont, P., Gardeur, J.N., Marie, M., 2010. Effects of photothermal kinetics and amplitude of photoperiod decrease on the induction of the reproduction cycle in female Eurasian perch (Perca fluviatilis). Aquacult. 322, 169 - 176.

Abi-Ayad, S.M., 1998. Etude expérimentale de la biologie de la reproduction de la perche fluviatile (Perca fluviatilis). Effet de la composition en acides gras de la série (n-3) de l'alimentation des géniteurs sur la qualité des oeufs et des larves. $\mathrm{PhD}$ thesis Liège, Belgium.

Asahina, K., Zhu, Y., Aida, K., Higashi, T., 1991. Synthesis of 17a,21-dihydroxy-4-pregnen-3,20-dione, 17a,2003-dihydroxy-4-pregnen-3-one, and 17a,200,21-trihydroxy-4-pregnen-3-one in the ovaries of 
tobi-numeri dragonet, Repomucenus beniteguri, Callionymidae Teleostei. In: Scott A.P., Sumpter J.P., Kime D.E. and Rolfe M.S. Reproductive Physiology of Fish, Sheffield, pp. 80-82.

Balon, E.K., 2004. About the oldest domesticates among fishes. J. Fish Biol. 65, 1 - 27.

Barton, B.A., 2002. Stress in fishes: a diversity of responses with particular reference to changes in circulating corticosteroids. Integ. And Comp. Biol. 42, 517 - 525.

Bell, J.G., Farndale, B.M., Bruce, M.P., Navas, J.M., Carillo, M., 1997. Effect of broodstock dietary lipid on fatty acid compositions of eggs from sea bass (Dicentrarchus labrax). Aquacult. 149, 107 - 119.

Brummett, R., Angoni, D., Pouomogne, V., 2004. On-farm and on-station comparison of wild and domesticated Cameroonian populations of Oreochromis niloticus. Aquacult. 242, 157 - 164.

Ciesla, M., Jonczyk, R., Gozdowski, D., Sliwinski, J., Rechulicz, J., Andrzejewski, W., 2013. Changes in ide (Leuciscus idus) female's reproductive parameters after stimulation with carp pituitary homogenate (CPH) and Ovopel: the effect of domestication?. Aquacult. Int. 22, 77 - 88.

Dannewitz, J., Petersson, E., Dahl, J., Prestegaard, T., Lof, A., Jarvi, T., 2004. Reproductive success ofhatcheryproduces and wild-born brown trout in an experimental stream. J. Appl. Ecol. 41, 355 - 364.

Digard, J.P., 2003. La domestication animale revisitée par l'anthropologie. Bulletin de la Soci. Zool. de France. $128,283-296$.

Douxfils, J., Mathieu, C., Mandiki, S.N.M., Milla, S., Henrotte, E., Wang, N., Vandecan, M., Dieu, M., Dauchot, N., Pigneur, L.M., Li, X., Rougeot, C., Melard ,C., Silvestre, F., Van Doninck, K., Raes, M., Kestemont, P., 2011. Physiological and proteomic evidences that domestication process differentially modulates the immune status of juvenile Eurasian perch (Perca fluviatilis) under chronic confinement stress. Fish Shellfish Immun. 31, 1113 - 1121.

Fontaine, P., 2004. Eurasian perch culture, a way of diversification for freshwater aquaculture. J. Anim. Prod. $17,189-193$.

Fontaine, P., 2009. Development of European inland fish culture and domestication of new species. Cah. Agric. $18,144-147$.

Fontaine, P., Wang, N., Hermelink, B., 2015. Broodstock management and control of the reproductive cycle. In: Kestemont P., Dabrowski K., Summerfelt F.C. (Eds.), Biology and culture of percid fishes. Springer, Dordrecht, pp. 103-122.

Fostier, A., Jalabert, B., 1986. Stereoidogenesis in rainbow trout (Salmo gairdneri) at various preovulatory stages: changes in plasma hormone level and in vivo responses of the ovary to salmon gonadotropin. Fish Physiol. Biochem., 2, 87 - 99.

Hassin S., de Monbrison, D., Hanin Y., Elizur A., Zohar Y., Popper D.M., 1997. Domestication of the white grouper Epinephlus aeneus, 1. Growth and reproduction. Aquacult. 156, 305 - 316.

Henrotte, E., Mandiki, R.S.N.M., Prudencio, A.T., Vandecan, M., Mélard, C., Kestemont, P., 2010. Egg and larval quality, and egg fatty acid composition of Eurasian perch breeders (Perca fluviatilis) fed different dietary DHA/EPA/AA ratios. Aquacult. Res. 41, 53 - 61.

Izquierdo, M.S., Fernández-Palacios, H., Tacon, A.G.J., 2001. Effect of broodstock nutrition on reproductive performance of fish. Aquacult. 197, 25 - 42.

Jonsson, B., Jonsson, N., 2006. Cultured Atlantic salmon in nature: a review of their ecology and interaction with wild fish. ICES J. Mar. Sci. 63, 1162 - 1181. 
Kestemont, P., Cooremans, J., Abi-Ayad, S.M., Mélard, C., 1999. Cathepsin L in eggs and larvae of perch Perca fluviatilis: variations with developmental stage and spawning period. Fish Physiol. Biochem. 21, 59 - 64. Kestemont, P., Henrotte, E., Wang, N., Hamza, N., Paulsen, H., Overton, J., 2008. Feeding and nutrition of European percid broodstock and early life stages. In: Fontaine P., Kestemont P., Teletchea F.and Wang N. (Eds.), Procceding of abstracts and short communications of the workshop Percid Fish Culture From Research to Production. Namur, pp. 28-34.

King, V.W., Thomas, P., Sullivan, C.V., 1994. Hormonal regulation of final maturation of striped bass oocytes in vitro. Gen. Comp. Endocrinol. 96, 223 - 233.

Kouril, J., and Hamackova, J., 1999. Artificial of perch propagation of European perch (Perca fluviatilis) by means of a GnRH analogue. Czech J. Anim. Sci. 44, 309 - 316.

Krejszeff, S., Targońska, K., Żarski, D., Kucharczyk, D. 2009. Domestication affects spawning of the ide (Leuciscus idus) preliminary study. Aquacult. 295, 145 - 147.

Kristan, J., Stejskal, V., Policar, T., 2012. Comparison of reproduction characteristics and broodstock mortality in farmed and wild Eurasian Perch (Perca fluviatilis L.) females during spawning season under controlled conditions. Turkish J. Fish. Aquat. Sci. 12, 191 - 197.

Langeron, M., 1942. Précis de Microscopie: Technique-Expérimentation-Diagnostic. Masson et Cie, Paris. 1339 pp (in French).

Lubzens, E., Cerda, J., Young, G., Bobe, J., 2010. Oogenesis in teleost fish: how fish eggs are formed. Gen. Comp. Endocrinol. 165, 367 - 389.

Mandiki, S.N.M., Babiak, I., Bopopi, J.M., Leprieur, F., Kestemont, P., 2005. Effects of sex steroids and their inhibitors on endocrine parameters and gender growth differences in Eurasian perch (Perca fluviatilis) juveniles. Steroids. 70, 85 - 94.

Migaud, H., Fontaine, P., Sulistyo, I., Kestemont, P., Gardeur, J.N., 2002. Induction of out-of-season spawning in Eurasian perch Perca fluviatilis: effects of rates of cooling and cooling durations on female gametogenesis and spawning. Aquacult. 205, 253 - 267.

Migaud, H., Mandiki, R., Gardeur, J.N., Kestemont, P., Fontaine, P., 2003. Synthesis of sex steroids in final oocyte maturation and induced ovulation in female Eurasian perch, (Perca fluviatilis). Aquat. Living Resour. 16, 380 - 388.

Milla, S., Mandiki, R., Hubermont, P., Rougeot, C., Melard, C., Kestemont, P., 2009a. Ovarian steroidogenesis inhibition by constant photothermal conditions is caused by a lack of gonadotropin stimulation in Eurasian perch. Gen. Comp. Endocrinol. 163, 242 - 250.

Milla, S., Wang, N., Mandiki, R., Kestemont, P., 2009b. Corticosteroids: friends or foes of teleost fish reproduction? Comp. Biochem. Physiol. A. 153, 242 - 251.

Modesto, T., Canario, A.V.M., 1993. The sex steroids of toadfish, (Halobatrachus didactylus). In Abstr. 12th Int. Congr. Comp. Endocrinol. Toronto.

Nagahama, Y., 1987. Endocrine control of oocyte maturation. In Hormones and Reproduction in Fishes, Amphibians, and Reptiles. Edited by D.O. Norris and R.E. Jones. pp. 171- 201. Plenum, New York, USA.

Noaksson, E., Tjarnlund, U., Bosveld, A.T.C., Balk, L,. 2001. Evidence for endocrine disruption in Perch (Perca fluviatilis) and Roach (Rutilus rutilus) in a remote Swedish lake in the vicinity of a public refuse dump Toxicol. And Appl. Pharmacol. 174, 160 - 176. 
Pickering, A.D., Pottinger, T.G., 1989. Stress responses and disease resistance in salmonid fish: effects of chronic elevation of plasma cortisol. Fish Physiol. Biochem. 7, 253 - 258.

Pickering ,A.D., Pottinger, T.G., 1997. Genetic basis to the stress response: selective breeding for stress-tolerant fish. In: Fish stress and health in aquaculture, G.K. Iwama, A.D. Pickering, J.P. Sumpter, C.B. Schreck (eds), 171-193. Cambridge University Press, Cambridge, UK.

Price, E.O. 1984. Behavioral aspects of animal domestication. Q. Rev. Biol. 59, 1 - 32.

Ramezani-Fard, E., Kamarudin, M.S., Harmin, S.A., 2013. Endocrine control of oogenesis in teleosts. Asian J. Anim. Vet. Adv. 8, 205 - 215.

Randák, T., Kocour, M., Žlábek, V., Policar, T., Jarkovský, J., 2005. Effect of culture conditions on reproductive traits of brown trout Salmo trutta 1. Bull. Fr. Pêche Piscic. 383, 1-12.

Rinchard, J., Kestemont, P., 1996. Comparative study of reproductive biology in single and multiple spawner cyprinid fish: I. Morphological and histological features. J. Fish Biol. 49, 883 - 894.

Salze, G., Tocher, D.R., Roy, W.J., Robertson, D.A., 2005. Egg quality determinants in cod (Gadus morhua L.): egg performance and lipids in eggs from farmed and wild broodstock. Aquacul. Res. 46, 1488 - 1499.

Schreck, C.B., 2010. Stress and fish reproduction: The roles of allostasis and hormesis. Gen. Comp. Endocrinol. $165,549-556$

Setälä, J., Laitinen, J., Virtanen, J., Saarni, K., Nielsen, M., Honkanen, A., 2008. Spatial integration of freshwater fish markets in the Northern Baltic Sea area. Fish. Res. 92, 196 - 206.

Stanton, M.G., 1968. Colorimetric determination of inorganic phosphate in the presence of biological material and adenosine triphosphate. J. Anal. Biochem. 22, 27 - 34.

Thomas, P., 1988. Changes in the plasma levels of maturationinducing steroids in several perciform fishes during induced ovulation. Am. Zool. 28, 53 - 63.

Tymchuk, W.E., Biagi, C., Withler, R., Devlin, R.H., 2006. Growth and behavioral consequences of introgression of a domesticated aquaculture genotype into a native strain of Coho Salmon. T. Am. Fish. Soc. $153,442-455$.

Vandeputte, M., Prunet, P., 2002. Génétique et adaptation chez les poissons : domestication, résistance au stress et adaptation aux conditions de milieu. INRA Prod. Anim. 15, 365 - 371.

Volckaert, F.A.M., Hellemans, B., Batargias, C., Louro, B., Massault, C., Van Houdt, J. K.J, Haley, C., de Koning, D.J. Canario, A.V.M., 2012. Heritability of cortisol response to confinement stress in European sea bass dicentrarchus labrax. Genet. Select. Evol. 44, 15.

Wallace, R.A., Selman, K., 1981. Cellular dynamic aspects of oocyte growth in teleosts. Am. Zool. 21,325 343.

Watson, L., 2008. The European market for perch (Perca fluviatilis). In: P. Fontaine, P. Kestemont, F. Teletchea and N. Wang (Eds.), Proceeding of abstracts and short communications of the workshop. Percid Fish Culture from Research to Production, Namur, Belgium, 10 - 14.

Withler, R.E., Beacham, T.D., 1994. Genetic variation in body weight and flesh colour of coho salmon (Oncorhynchus kisutch) in British Columbia. Aquacult. 119, 135 - 148.

Yaron, Z., Gur, G., Melamed, P., Rosenfeld, H., Elizur, A., Levavi-Sivan, B., 2003. Regulation of fish gonadotropins. Int. Rev. Cytol. 225, 131 - 185. 
Fig. 1. The photothermal program (adapted from Fontaine et al. 2015). The photothermal program was used to induce perch reproduction. The dark curve corresponds to the photoperiod variations. The light curve corresponds to the temperature variations. T0, T35, T157, T295 are the four sampling times which represent days 0, 35, 157 and 295 after the start of the experiment.

Fig. 2. GSI changes (\%) in F1 and domesticated females. ( 9 females per sampling period + Standard deviation). Sampling times T0, T35, T157 and T295 correspond respectively to days $0,35,157$ and 295 after the beginning of the photothermal program. The asterisk represents a significant difference between the 2 fish populations $(\mathrm{p}<0.05)$.

Fig. 3. Different developmental stages observed in domesticated and F1 perch female ovaries. (9 females per sampling time + Standard deviation). D and F1 refer to Domesticated and F1 respectively. Sampling periods T0, T35, T157 and T295 correspond respectively to days $0,35,157$ and 295 after the beginning of the photothermal program.

Fig. 4. Plasma sexual steroids and vitellogenin levels variation. (A) E2 levels variation (ng/mL) in F1 and domesticated females. (B) Testosterone levels variation (ng/mL) in F1 and domesticated females. (C) Vitellogenin levels variation ( $\mu \mathrm{g} \mathrm{ALP/mL)} \mathrm{in} \mathrm{F1} \mathrm{and}$ domesticated females. (D) $11 \mathrm{KT}$ variations $(\mathrm{pg} / \mathrm{mL})$ in F1 and domesticated females. (9 females per time per population + standard deviation). Sampling periods T0, T35, T157 and T295 correspond respectively to days $0,35,157$ and 295 after the beginning of the photothermal program. The asterisk $(*)$ represents a significant difference $(p<0.05)$ and $(* *)$ $(\mathrm{p}<0.001)$.

Fig.5. Plasma DHP and aromatase activity. (A) Plasma DHP levels (ng/mL) variation in domesticated and $\mathrm{F} 1$ perch females. (B) Aromatase activity variation (fmol/min.mg) in domesticated and F1 perch females. ( 9 females per time per population + standard deviation). Sampling periods T0, T35, T157 and T295 correspond respectively to days 0, 35, 157 and 295 after the beginning of the photothermal program.

Fig. 6. GnRH 3 and gonadotropins gene expression quantification in the brain and pituitary. (A) GnRH 3 mRNA levels in F1 and domesticated female brains. (B) GnRH 3 mRNA levels in F1 and domesticated female pituitaries. (C) $\beta F S H$ mRNA levels in F1 and domesticated female brains. (D) $\beta F S H$ mRNA levels in F1 and domesticated female pituitaries. (E) $\beta \mathrm{LH}$ mRNA levels in F1 and domesticated female brains.. (F) $\beta \mathrm{LH}$ mRNA levels in F1 and domesticated female pituitaries. ( 9 females per time per population + standard deviation). Sampling periods T0, T35, T157 and T295 correspond respectively to days $0,35,157$ and 295 after the beginning of the photothermal program. mRNA levels have been quantified by q-PCR. The asterisk $\left(^{*}\right)$ represents a significant difference $(\mathrm{p}<0.05)$ and $(* *)(\mathrm{p}<0.001)$.

Fig. 7. Cortisol levels variation (ng/mL) in F1 and domesticated females. ( 9 females per time per population + standard deviation). Sampling times T0, T35, T157 and T295 correspond respectively to days $0,35,157$ and 295 after the beginning of the photothermal program. The asterisk $(*)$ represents a significant difference $(\mathrm{p}<0.05)$. 
698

699 